\title{
Voyager passes Uranus, Giotto rescued
}

\section{Washington}

VOYAGER project scientists are ecstatic about the first flood of data sent back by the Voyager 2 spacecraft during its closest encounter with Uranus.

By Monday, the total number of moons around Uranus had risen to 15 , only five of which were known before the Voyager mission. A tenth ring was also discovered just inside the brightest and outermost ring around the planet, and there is evidence for ten additional faint rings. Voyager's telemetry also indicates the presence of high-energy radiation belts similar to those around Saturn, Jupiter and Earth.

The debate over the strength of Uranus' magnetic field has been resolved by Voyager. According to Dr Ellis Miner, deputy Voyager project manager at the Jet Propulsion Laboratory (JPL) in Pasadena, California, the magnetic field strength is 0.25 gauss at the cloud top. The field has a peculiar orientation, tilted 55 degrees from the rotational axis, so that one of the polar regions is pointing towards the Sun.

According to A.J. Dessler, director of the Space Science Laboratory at Marshall Space Flight Center, there is "hardly any glory for anybody" in the 0.25 gauss figure. The proponents of a strong cloud top magnetic field were expecting a figure greater than 0.6 gauss and the weak magnetic field proponents were looking for something in the range of $4 \times 10^{-5}$ gauss. Dessler believes that the 0.25 figure may be revised upwards when the data from Voyager are further analysed.

Pictures sent back by Voyager 2 of Miranda, a 310-mile-wide satellite closest to the planet's surface of the five major moons, were causing wonderment among members of the photographic interpretation team.

"If you took all the bizarre geology in the Solar System and put it back into one object, that would be Miranda", Dr Laurence Soderblom of the US Geological Survey was quoted as saying.

Miranda's surface appears to be a hodgepodge of valleys, cliffs, fault zones, craters and broad terraces. The peculiar mix of features was so startling, mission scientists were loath to speculate whether external or internal forces were involved in creating the formations.

An unexpected event of Friday in the midst of the Voyager flyby gave the National Aeronautics and Space Administration (NASA) and the European Space Agency (ESA) a chance to show how well they can cooperate.

ESA ground controllers were ex- periencing communications problems with Giotto because of a pointing problem with one of the spacecraft's antenna systems. As it happened, a large number of the Giotto team were at JPL for meetings, and after a brief consultation, NASA turned over a portion of the Deep Space Network of tracking stations to ESA. The Giotto scientists at JPL established a direct link with Giotto mission control in Darmstadt, West Germany, and the problem was resolved within hours with no loss of data from either mission. Joseph Palca

\section{Asbestos ban?}

\section{Washington}

ThE US Environmental Protection Agency (EPA) has succumbed to growing pressure to ban all uses of asbestos. The agency last week formally proposed a regulation that would place an immediate ban on asbestos in five use categories, and phase out all other uses within 10 years. All forms of asbestos are treated similarly by the proposed regulation.

Regulations to ban the use of asbestos, based on studies by the Consumer Product Safety Commission and the National Academy of Sciences, were first drafted two years ago. Both studies essentially concluded that no safe lower limit for exposure could be established and led EPA to decide that asbestos should be banned where substitutes are available. But the regulations were held up by objections on cost grounds from the Office of Management and Budget; EPA's administrator, Lee Thomas, said last week that the new proposal had resolved the budget difficulties.

A final decision on whether to go ahead with the ban will be taken after a 90-day comment period. A spokesman for the Asbestos Information Association said a ban would be "totally unjustified and out of step with the international consensus on current use". The association points out that the estimated $3,300-12,000$ deaths each year in the United States that can be attributed to asbestos are the result of exposures of 20 years ago and more. Nevertheless, EPA estimates that the ban will save 1,000 lives before the end of the century, and officials say the ban now has a lot of momentum. The EPA proposal would ban immediately manufacturing importing and end-processing of asbestos roofing felt, flooring felts and tiles, asbestos cement pipe and fittings, and asbestos clothing. Other uses would be phased out over 10 years.

Tim Beardsley
SDI

\section{Software rows}

Washington

THE difficulty of developing reliable software for the Strategic Defense Initiative (SDI) has surfaced once again. An SDI advisory panel had concluded that contractors working on preliminary design concepts for a space-based shield against nuclear weapons have not paid sufficient attention to the problem. The SDI organization appears to have taken the panel's criticism seriously; officials have been quoted as saying that the amount spent on software problems will be increased.

Critics of SDI hold that contractors have failed to address the issue adequately because the job simply cannot be done. The advisory panel, known as the Eastport Group, does however maintain (on the basis of qualitative argument) that reliable software can be tested and developed within the next several years.

SDI software must keep track of possibly thousands of warheads and many more decoys, coordinating multiple layers of weapons systems and sensors in real time to stop as many missiles as possible from reaching their target. Those convinced that the problem cannot be solved argue that the system cannot be tested under real conditions and that it must work first time. Analogies are made with the software failures that have often delayed space shuttle launches, for example. David Parnas, of the University of Victoria in British Columbia, resigned from the Eastport Group last year on just these grounds. Parnas now says that the group has not refuted his arguments and that he is "amazed at how little thought" has been given to his publicly stated criticisms; he accuses administrators at the SDI organization of incompetence.

One central issue is the extent to which the system functions as a single coordinated whole rather than as several functionally-autonomous subunits with built-in redundancy. A distributed system would be less vulnerable to the inevitable software errors. The Eastport Group favours a distributed system because it would make the software problem more tractable; the contractors' ideas so far, however, are based on more tightly coordinated systems.

Parnas believes the contractors chose a coordinated system because they realized SDI would not work otherwise, whereas the Eastport Group went for a distributed system because the software development would otherwise be too difficult; "they're both right". The Eastport Group says that contractors have too closely followed model system descriptions intended only for illustrative purposes that were included in the two-year-old Fletcher report on the feasibility of SDI. Tim Beardsley 